\title{
Risk-Averse Newsvendor Model with Strategic Consumer Behavior
}

\author{
Tie Wang ${ }^{1,2}$ and Qiying $\mathrm{Hu}^{3}$ \\ ${ }^{1}$ School of Mathematics, Liaoning University, Shenyang, Liaoning 110036, China \\ ${ }^{2}$ School of Management, Shanghai University, Shanghai 200444, China \\ ${ }^{3}$ School of Management, Fudan University, Shanghai 200443, China \\ Correspondence should be addressed to Tie Wang; wangt_1997@163.com
}

Received 1 February 2013; Revised 8 July 2013; Accepted 20 July 2013

Academic Editor: Mohammad Khodabakhshi

Copyright (C) 2013 T. Wang and Q. Hu. This is an open access article distributed under the Creative Commons Attribution License, which permits unrestricted use, distribution, and reproduction in any medium, provided the original work is properly cited.

\begin{abstract}
The classic newsvendor problem focuses on maximizing the expected profit or minimizing the expected cost when the newsvendor faces myopic customers. However, it ignores the customer's bargain-hunting behavior and risk preference measure of the newsvendor. As a result, we carry out the rational expectation (RE) equilibrium analysis for risk-averse newsvendor facing forwardlooking customers who anticipate future sales and choose purchasing timing to maximize their expected surplus. We propose the equations satisfied by the RE equilibrium price and quantity for the risk-averse retailer in general setting and the explicit equilibrium decisions for the case where demand follows the uniform distribution and utility is a general power function. We identify the impacts of the system parameters on the RE equilibrium for this specific situation. In particular, we show that the RE equilibrium price for some risk-averse newsvendors is lower than for a risk-neutral retailer and the RE equilibrium stocking quantity for some risk-averse newsvendors is higher than for a risk-neutral retailer. We also find that the RE equilibrium sale price for a risk-averse newsvendor is decreasing in salvage price in some situations.
\end{abstract}

\section{Introduction}

1.1. Motivation. Strategic consumer behavior is widely acknowledged by the retailer and deeply influenced ordering, pricing, and other marketing decisions for the retailer. A strategic consumer chooses between a purchase at the initial full price with the possibility, if inventory remains, of a later purchase at a salvage price. Recently, it has attracted much attention by the researchers from supply chain management and revenue management when the decision maker is risk neutral. Evidently, not all decision makers are risk neutral. Indeed, some experimental evidence suggests that for some products, the so-called high-profit products, the decision makers are risk averse; see Schweitzer and Cachon [1] for more details. However, according to our knowledge, few considered the combined impacts of strategic consumer behavior and risk aversion on the pricing and ordering decisions for the newsvendor.

In this paper we study a risk averse retailer's stocking and pricing in the presence of strategic consumers. This paper has three main objectives. First, we obtain the rational expectation (RE) equilibria under the rational expectations hypothesis firstly proposed by Muth [2] for the risk-averse retailer. It states that economic outcomes do not dier systematically from what people expect them to be. We begin with the classic newsvendor setting, which is a fundamental building block in the literature, and proceed to incorporate strategic demand and risk aversion into the model. Second, we would like to introduce a specific risk averse utility-power utility to investigate explicitly the impacts of strategic consumer behavior and risk aversion on newsvendor decisions. The third objective is to study the impact of systems parameters on the RE equilibria.

1.2. The Literature Review. The classic newsvendor problem is a crucial building block of the stochastic inventory theory because of its simple and elegant structure as well as its rich managerial insights. It assumes that if any inventory remains at the end of the period, a discount is used to sell it or it is disposed of. If the order quantity is smaller than 
the realized demand, the newsvendor loses some profit. The classic newsvendor model reflects many real situations and is often used to help make decisions in many industries, such as fashion and sporting, both at the manufacturing and sale level. It has been extensively studied over decades with extensions including different objectives and utility functions, multiple products with substitution, multiple locations, different pricing, and marketing strategies. Khouja [3] builds a taxonomy of the single-period problem literature and delineates the contribution of the different extensions and suggests some future directions for research.

One important extension to the classic newsvendor model is the interface of marketing and operation that provides an important tool for examining how operational problem interacts with marketing issues to influence decisionmaking at the firm level. There are three research streams about this extension, one is the newsvendor problem with pricing whose demand is stimulated by sale price, one is the newsvendor problem with inventory whose demand is driven by inventory, and the other is the newsvendor problem with marketing whose demand is stimulated by other marketing instruments. Petruzzi and Dada [4] provided a good review about the newsvendor problem with pricing that synthesizes existing results and develops additional results to enrich existing knowledge base. Yao et al. [5] extended this model to increasing price elasticity (IPE) mean demand situation and used this condition to investigate the newsvendor problem with pricing under stochastic demand distribution class with increasing generalized failure rate (IGFR) that was presented in Lariviere and Porteus [6] to study supply coordination with wholesale price contract based on the classic newsvendor model.

The first paper that takes the inventory as a marketing measure is by Gerchak and Wang [7]. They extended the classical newsvendor model to include endogenous, inventorydependent demand for aexogenous price. The demand form in their paper was multiplicative demand that models actual demand as a deterministic multiple of a base random variable with a fixed probability distribution. Balakrishnan et al. [8] investigated the deterministic counterpart for the newsvendor problem with inventory. Dana and Petruzzi [9] extended the classic newsvendor model by assuming that expected utility maximizing consumers choose between visiting the firm and consuming an exogenous outside option. They modeled the stochastic demand as multiplicative form depending inventory and price and found that the firm holds more inventories, provides a higher fill rate, attracts more customers, and earns higher profits when it internalizes the effect of its inventory on demand. Recently, Balakrishnan et al. [10] extended the newsvendor problem to general inventory-dependent demand distribution with given price and showed that demand stimulation has the effect of increasing the target service level beyond the classical newsvendor model's critical ratio. Similar to Dana and Petruzzi [9], they also addressed the problem of jointly optimizing both stocking quantity and price for demand-stimulating products using a multiplicative model to represent the influence of price and stocking quantity on the demand distribution. For this model, they showed that the pricing and stocking decision can be determined sequentially, with the optimal policy setting higher prices and stock levels than both the functional policies (demand-driven and critical fractile). Liu et al. [11] study the impact of supply reliability on a retail firm's performance under joint marketing and inventory decisions. They established a necessary and sufficient condition under which the maximum unit cost a firm is willing to pay to improve supply reliability increases in product price and showed that for two products with the same price, a firm is willing to pay more to improve supply reliability for the product with higher product cost. They also found that a product with a lower marketing cost function always benefits more from improved supply reliability than a product with a higher marketing cost function. Taylor [12] showed that when demand is influenced by retailer sales effort, a properly designed target rebate and return contract achieves coordination and a win-win outcome. Krishnan et al. [13] investigated similar problem as Taylor's [12]. But the retailer chooses inventories ex ante and promotional effort ex post in their paper.

Taking advertising as a special marketing instrument, Gerchak and Parlar [14] studied the newsvendor model when multiplicative demand has a distribution with a mean that is specific concave and increasing in advertising expenditure. They developed a mixed optimization technique which combines simulation with the first order condition to solve the previous problem. Khouja and Robbins [15] extended the model presented by Gerchak and Parlar [14] to three cases of demand variation as a function of advertising expenditure: (1) demand has constant variance, (2) demand has constant coefficient variation, and (3) demand has an increasing coefficient variation. They investigated the newsvendor problem with advertising under multiplicative demand and obtained the optimal advertising premium and ordering quantity by maximizing the expected profit or maximizing the probability of achieving a target profit under the previous three situations using particular mean demand and discussed that the optimal advertising decisions for maximizing profit is increased with the profit margin. Recently, Wang and Zhou [16] discussed the supply chain coordination with newsvendor under advertisement sensitive demand and proposed an improved revenue-sharing contract to achieve the supply chain coordination. Wang et al. [17, 18] investigated the supply chain coordination with a newsvendor under specific advertisement and price sensitive demand using improved revenue sharing contract and combined return and sales rebate/penalty contract.

It is natural to incorporate the decision maker's risk attitude in newsvendor model because anybody has his own preference when he makes a decision. Many planners are willing to trade off lower expected profit for downside protection against possible losses. The literature about riskaverse newsvendors is fewer than those about risk-neutral newsvendors. Lau [19] analyzed the classical newsvendor model under two different objectives. In the first objective, the focus is on maximizing the decision maker's expected utility of total profit. The second objective is the maximization of the probability of achieving a certain level of profit. Eeckhoudt et al. [20] explored the newsvendor model with 
increasing, concaves and thrice differentiable utility function, and showed that the optimal ordering quantity in their environment is smaller than the risk-neutral optimal ordering quantity and decrease in risk-aversion level. Keren and Pliskin [21] derived the first order conditions for optimality for the problem of a risk-averse expected-utility maximizer newsvendor. They solved a special case where the utility function is any increasing differentiable function, and the random demand is uniformly distributed by using these conditions. Agrawal and Seshadri [22] explored the effect of risk aversion on the pricing and ordering decision with emergency ordering. They modeled the risk aversion as a twice continuous differentiable and increasing concave utility function. Chen and Federgruen [23] analyzed the meanvariance trade-offs in newsvendor model as well as some standard infinite horizon inventory problems. Choi et al. [24] studied the same problem, but they explore all kinds of risk attitudes and focus on the profit and instantiate the case with shortage penalty and safety-first objective.

Some research papers use the conditional value at risk (CVaR) as a special risk-averse metrics to investigate the newsvendor problem. Gotoh and Takano [25] analyzed the minimization of the CVaR for single and multiple products cases. Following the condition for mean demand presented in Yao et al. [5], Chen et al. [26] investigated the joint pricing and ordering strategies for newsvendor under CVaR decision criteria which is based on the maximization of the CVaR. They provided sufficient conditions for the existence and uniqueness of optimal policies for both additive and multiplicative demands and performed the comparative statics which show the monotone properties and other characteristics of the optimal pricing and ordering decisions. They also compared their results with those for a risk-neutral newsvendor. In addition, Ahmed et al. [27] used the general coherent risk measure as a risk-averse preference to investigate both the single period and multiperiod inventory problems.

Behavioral operations management is an emerging area to the study of operations that explicitly incorporates social and cognitive psychological theory. It is the study of human behavior and cognition and their impacts on operating systems and processes. So far, there are three review papers about behavior operation. Gino and Pisano [28] explored the theoretical and practical implications of incorporating behavioral and cognitive factors into models of operations management and suggest fruitful avenues for research in behavioral operations. Bendoly et al. [29] highlighted theoretical constructs and empirical phenomena from behavioral economics/judgment and decision making, industrial and organizational psychology, group dynamics, and system dynamics and provided a guide for where to go to learn more about each body of knowledge. Shen and $\mathrm{Su}$ [30] reviewed current models of customer behavior in the revenue and suction literature and suggested several future research directions. Su [31] proposed a decision framework of bounded rationality, in which decision makers are prone to errors and biases. He applied this framework to the classic newsvendor model and characterized the ordering decisions made by a roundedly rational decision maker. He identified systematic biases and offered insight into when overordering and underordering may occur. Su [32] studied the dynamic pricing of finite inventories with a heterogeneous population of strategic as well as myopic customers and showed that depending on the customer composition, optimal price paths could involve either markups or markdowns. Su and Zhang [33] investigated the impact of strategic customer behavior on supply chain performance. Applying rational expectations hypothesis to the newsvendor model, they analyzed the previous model by looking for rational expectations (RE) equilibria, which satisfies (i) given their expectations of future availability, consumers make their purchase (or waiting) decisions, (ii) given his expectations of consumers' willingness to pay, the newsvendor makes his pricing and stocking decisions, and (iii) everyone's expectations are consistent with actual outcomes. They show that in RE equilibrium, the newsvendor will invest in less inventory and charge a lower regular sales price. The newsvendor's performance is substantially affected by the consumers' waiting behavior. To alleviate this impact, they study two mechanisms-quantity commitment and price commitment-embedded in supply chain management. Su and Zhang [34] studied the role of product availability in attracting consumer demand. They base on a newsvendor but assume that consumers must incur some search cost in order to visit the seller. The seller sets an observable price and an unobservable stocking quantity. Consumers anticipate the likelihood of stockout and determine whether to visit the seller. They characterize the RE equilibrium in this game and show that the seller can improve profits by providing inventory information or availability guarantees. Lai et al. [35] examine the impact of a posterior price matching policy in which the seller guarantees to reimburse the price difference to a consumer who buys a product before the seller marks it down on strategic consumer's purchasing behavior, a seller's pricing and inventory decisions and their expected payoffs, assuming that the seller cannot credibly commit to a price path but can implement a posterior price matching policy.

Our model differs from the previous papers in the following aspects. Firstly, we explore the case where the seller is risk averse and consumers are forward looking. Secondly, we obtain an analytical solution for a specific situation where demand follows the uniform distribution and utility is a power function to illustrate the combined impacts of strategic consumer behavior and risk aversion on newsvendor's decisions. Thirdly, we investigate the influence of system parameters on RE equilibrium and compare them to the existing results about the risk-averse newsvendor with myopic consumers and the risk-neutral newsvendor with strategic consumers. Based on the analysis of the model, we obtain the following insights: (1) the RE equilibrium ordering quantity and sale price are all lower than those for a risk-averse newsvendor with myopic customers, (2) the optimal ordering quantity for a risk-averse newsvendor facing myopic consumers is higher than the RE equilibrium stocking quantity for a risk-neutral retailer, (3) the RE equilibrium sale price for some risk-averse newsvendors is lower than for a risk-neutral retailer, and the RE equilibrium ordering quantity for some risk-averse newsvendors is higher than for a risk-neutral retailer, (4) in some situations, the 
TABLE 1: Notions used in this paper.

\begin{tabular}{ll}
\hline$c$ & Product cost \\
$v$ & Customer valuation \\
$p$ & Retail price \\
$p_{\mathrm{rn}}$ & RE equilibrium price for risk-neutral retailer \\
$p_{\mathrm{ra}}$ & RE equilibrium price for risk-averse retailer \\
$s$ & Salvage price \\
$Q$ & Order quantity \\
$Q_{0}$ & $\begin{array}{l}\text { Optimal ordering quantity for risk-averse newsvendor } \\
\text { model with myopic customers }\end{array}$ \\
$Q_{\mathrm{rn}}$ & $\begin{array}{l}\text { RE equilibrium ordering quantity for risk-neutral } \\
\text { retailer }\end{array}$ \\
$Q_{\mathrm{ra}}$ & $\begin{array}{l}\text { RE equilibrium ordering quantity for risk-averse } \\
\text { retailer }\end{array}$ \\
$f(\cdot), F(\cdot)$ & $\begin{array}{l}\text { pdf and cdf of the distribution of stochastic demand } \xi \\
\pi(q)\end{array}$ \\
$U(\cdot)$ & $\begin{array}{l}\text { Profit function } \\
\text { Newsvendor's utility function }\end{array}$ \\
\hline
\end{tabular}

sale price in $\mathrm{RE}$ equilibrium for risk-averse newsvendor is decreasing in salvage price.

The remainder of this paper is organized as follows. Section 2 gives the model and derives RE equilibrium for a risk-averse newsvendor. Section 3 explores a specific case where demand follows the uniform distribution and utility is a power function. Section 4 presents the numerical examples to illustrate the model. Section 5 concludes the paper with future researches.

\section{The General Model}

In this section, we present the risk-averse newsvendor model with strategic customers. Notions used in this paper are given in Table 1 at the end of this part.

Our starting point is the classic newsvendor model. There is a single risk-averse retailer who must determine how many units of a product to order. The retailer faces a random demand $\xi \geq 0$, which has distribution $F$ and probability density function $f$. We assume that $f$ is continuous, $f(0)>0$ and $F(0)=0$. The risk-averse retailer has a utility function $U(\cdot)$. We assume $U(0)=0$ and $U^{\prime}(\cdot)>0, U^{\prime \prime}(\cdot)<0$, and each unit of the product costs $c$ but is valued by customer at $v$. Leftover units can be sold in an exogenous salvage market at $s$ per unit. We also assume $0<s<c<v$. Customers choose between buying immediately at full price or waiting for the sale at salvage price because they recognize that the product may become available on the salvage market at price $s$. If the regular retail price is too high, customers may find it worthwhile to wait for the sale, even if the product may be sold out by then.

Our model setup is similar to that in $\mathrm{Su}$ and Zhang [33]. Sequence of events are as the following. First, the riskaverse retailer privately forms his beliefs over customers' reservation prices and then optimally chooses the price and quantity given these beliefs. We also assume that customers may observe the retail price but do not observe the ordering quantity. Then, customers privately form beliefs over their chances of obtaining the product on the salvage market and then form their reservation prices based on these beliefs. Next, the random demand $\xi$ is realized. Then, sales occur at the full price $p$ (provided that the retail price $p$ does not exceed consumers reservation $r$ ). Finally, all remaining units are sold at the salvage price $s$.

We first describe the consumer's decision problem. Consider a particular consumer who forms the belief that he will obtain the product with probability $\xi_{\text {prob }}$ if he waits for the sale. Based on these expectations, the consumer's expected surplus if he faces an actual retail price $p$ is

$$
\max \left\{v-p,(v-s) \xi_{\text {prob }}\right\}
$$

The first term is his surplus from buying at the regular price $p$, and the second term is his expected surplus if he waits for the sale, where there is probability $\xi_{\text {prob }}$ that he earns surplus $v-s$ and probability $1-\xi_{\text {prob }}$ that he earns zero surplus (if the product is out of stock). Since the consumer chooses the more attractive option between buying and waiting, he will buy at price $p$ if and only if $v-p \geq(v-s) \xi_{\text {prob }}$. In other words, given his expectations $\xi_{\text {prob }}$, the consumer's reservation price for the product is

$$
r\left(\xi_{\text {prob }}\right)=v-(v-s) \xi_{\text {prob }} .
$$

We consider homogeneous customers who share the same beliefs $\xi_{\text {prob }}$ and the same reservation price $r$ and assume that consumers are risk neutral and they do not discount future payoff.

Next, we consider the retailer's decision problem to determine an ordering quantity $Q$ and a retail price $p$. Suppose that the seller expects that all customers have a reservation price $\xi_{r}$. Given these beliefs, it is clear that he will choose price and quantity as follows

$$
\begin{gathered}
p=\xi_{r}, \\
Q(p)=\arg \max _{Q} E[U(\pi(Q, p))],
\end{gathered}
$$

where $\pi(Q, p)=p \min (Q, \xi)+s(Q-\xi)^{+}-c Q=(p-$ $c) Q-(p-s)(Q-\xi)^{+}$is the profit for the risk-neutral newsvendor. Notice that given his expectations $\xi_{r}$, the retailer is essentially considering a fixed price and solving a riskaverse newsvendor problem.

The previous discussion establishes the relationship between the initial beliefs $\xi_{r}, \xi_{\text {prob }}$ and the subsequent decisions $p, Q, r$. After demand is realized, sales are generated according to these decisions. If their reservation price $r$ exceeds the retail price $p$, consumers are willing to buy at this price, so regular and salvage sales occur as in the riskaverse newsvendor model (i.e., $\min (Q, \xi)$ units are sold at price $p$ and the remaining are salvaged at price $s$ ); otherwise, all customers prefer to wait, no regular sales occur, and all units are salvaged at price $s$. The final requirement of our model is that these eventual outcomes (in terms of sales) should be consistent with all initial beliefs. This will be made clear in the following. 
We can obtain the following rational expectation equilibrium through the strategic interaction analysis between the risk-averse retailer and the customers.

Definition 1. A rational-expectations equilibrium for riskaverse newsvendor and risk-averse strategic consumers $\left(p, Q, r, \xi_{\text {prob }}, \xi_{r}\right)$ satisfies the following: (i) $v-r=(v-s) \xi_{\text {prob }}$, (ii) $p=\xi_{r}$, (iii) $Q=\arg \max _{Q} E[U(\pi(Q, p))]$, (iv) $\xi_{\text {prob }}=$ $F(Q)$, and $(\mathrm{v}) \xi_{r}=r$.

Conditions (i), (ii), and (iii) assert that under expectations $\xi_{\text {prob }}$ and $\xi_{r}$, the seller and all consumers will rationally choose the appropriate utility-maximizing actions, as specified in (2), (3), and (4). The last two conditions require that expectations must be consistent with outcomes. In (iv), the expectations $\xi_{\text {prob }}$ must concur with the actual probability of obtaining the product if an individual consumer waits for the sale. This actual probability can be calculated as follows. In equilibrium, the seller prices the product at consumers reservation price, so all consumers will buy the product. Therefore, if an individual consumer waits instead, this consumer will obtain the product if and only if $\xi \leq Q$, which occurs with probability $F(Q)$, as shown in (iv). Here, we have implicitly assumed efficient rationing: customers who wait for the sale have the highest priority to receive the product in the salvage market. This is reasonable because customers who are interested in a particular product and eagerly waiting for a sale are also the ones who are more likely to get the product when the sale actually takes place. Finally, in (v), the seller must correctly anticipate consumer's reservation price.

For risk-neutral newsvendor, Su and Zhang [33] derived the following result:

$$
\begin{gathered}
p=v-(v-s) F(Q), \\
Q=\arg \max _{Q} E[\pi(Q)] .
\end{gathered}
$$

They concluded that the optimal ordering quantity and retail price for the risk-neutral newsvendor facing strategic consumers must satisfy

$$
\begin{gathered}
p_{\mathrm{rn}}=s+\sqrt{(v-s)(c-s)}, \\
\bar{F}\left(Q_{\mathrm{rn}}\right)=\sqrt{\frac{c-s}{v-s}} .
\end{gathered}
$$

In the following proposition, we explore the relationship between the retail price and ordering quantity with the system parameters in RE equilibrium.

Proposition 2. Under the RE equilibrium for the risk-neutral newsvendor, the retail price $p_{\mathrm{rn}}$ is increasing in customer valuation, ordering cost, but is decreasing in salvage price, while the ordering quantity $Q_{\mathrm{rn}}$ is increasing in customer valuation, salvage price but is decreasing in ordering cost.

Proof. From (6) and (7), we immediately know that $p_{\text {rn }}$ is increasing in $v$ and $c, q_{\mathrm{rn}}$ is decreasing in $c$ and increasing in $v$.
Taking the derivative of $p_{\mathrm{rn}}$ with respect to $s$ leads to

$$
\begin{aligned}
\frac{d p_{\mathrm{rn}}}{d s} & =1-\frac{v+c-2 s}{2 \sqrt{(v-s)(c-s)}} \\
& \geq 1-\frac{2 \sqrt{(v-s)(c-s)}}{2 \sqrt{(v-s)(c-s)}}=0 .
\end{aligned}
$$

Notice that $v>c$; therefore, $\left(d p_{\mathrm{rn}} / d s\right)>0$ for all $s<c$, and $p_{\mathrm{rn}}$ is strictly increasing in salvage value $s$.

Taking the derivative of $\bar{F}\left(q_{\mathrm{rn}}\right)$ with respect to $s$ leads to

$$
\frac{d \bar{F}\left(q_{\mathrm{rn}}\right)}{d s}=\frac{(c-v)}{2(v-s)^{2} \sqrt{(c-s) /(v-s)}}<0 .
$$

Therefore, $\bar{F}\left(q_{\mathrm{rn}}\right)$ is decreasing in $s$; that is, $q_{\mathrm{rn}}$ is increasing in $s$.

The conditions for rational expectation (RE) equilibrium in Definition 1 can be reduced to a pair of equations for only $p$ and $Q$ in the following proposition.

Proposition 3. In the RE equilibrium, all consumers buy immediately, and the risk-averse newsvendor's retail price and order quantity are characterized by

$$
\begin{gathered}
v-p=(v-s) F(Q), \\
-(c-s) \int_{0}^{Q} U^{\prime}((p-s) x-(c-s) Q) f(x) d x \\
+(p-c) \int_{Q}^{+\infty} U^{\prime}((p-c) Q) f(x) d x=0 .
\end{gathered}
$$

Proof. Notice that the conditions for rational expectation (RE) equilibrium between risk-averse newsvendor and riskneutral strategic consumers in Definition 1 can be reduced to the following pair of equations for only $p$ and $Q$

$$
\begin{gathered}
v-p=(v-s) F(Q), \\
Q=\arg \max _{Q} E[U(\pi(Q))] .
\end{gathered}
$$

From the profit for the risk-neutral newsvendor, we can get

$$
\begin{aligned}
E[U(\pi(Q))]= & \int_{0}^{Q} U((p-s) x-(c-s) Q) f(x) d x \\
& +\int_{Q}^{+\infty} U((p-c) Q) f(x) d x .
\end{aligned}
$$


Hence,

$$
\begin{aligned}
& \frac{d E[U(\pi(Q))]}{d Q} \\
& =-(c-s) \int_{0}^{Q} U^{\prime}((p-s) x-(c-s) Q) f(x) d x \\
& \quad+(p-c) \int_{Q}^{+\infty} U^{\prime}((p-c) Q) f(x) d x, \\
& \frac{d^{2} E[U(\pi(Q))]}{d Q^{2}} \\
& \quad(c-s)^{2} \int_{0}^{Q} U^{\prime \prime}((p-s) x-(c-s) Q) f(x) d x \\
& \quad+(p-c)^{2} \int_{Q}^{+\infty} U^{\prime \prime}((p-c) Q) f(x) d x \\
& \quad-(p-s) f(Q) U^{\prime}((p-c) Q)<0 .
\end{aligned}
$$

Notice that

$$
\left.\frac{d E[U(\pi(Q))]}{d Q}\right|_{Q=0}>0, \quad \lim _{Q \rightarrow+\infty} \frac{d E[U(\pi(Q))]}{d Q}<0 .
$$

Therefore, there must be unique solution of $d E[U(\pi(Q))] /$ $d Q=0$ in $(0,+\infty)$.

From Proposition 3, we cannot know if a risk-averse newsvendor with a uniformly more concave utility function sets his $Q_{\text {ra }}$ to a lower value than a less risk-averse newsvendor, so a risk-averse newsvendor with a concave utility function sets $Q_{\mathrm{ra}}$ lower than a newsvendor who is risk neutral when the retailer faces strategic consumers. We also cannot know the relation of $p_{\text {ra }}$ between the risk-averse newsvendors, so the relation of $p_{\text {ra }}$ between risk-averse and risk-neutral newsvendors. In addition, it is meaningful to understand fully the interaction between strategic consumers behavior and risk aversion.

For readers' convenience, in Table 1 we list the notations used in this paper.

\section{Rational Expectation Equilibrium for Power Utility and Uniform Distribution}

It is instructive to compare the equilibrium price and quantity in our model with that in the risk-averse newsvendor model, where customers are not strategic and are willing to pay their valuation $v$ for the product (so the retailer also charges $v$ ). It is also significant to compare the equilibrium price and quantity in our model with that in the classic newsvendor model or in the risk-neutral newsvendor model with strategic consumers. To derive structural results and generate managerial insights into the equilibrium decisions of the risk-averse newsvendor problem with strategic consumers, in the following, we present the specific results for the case where demand follows the uniform distribution, and retailer's utility is a power function. Without loss of generality, we assume $F(x)$ is distributed uniformly in $[0, A]$ with $A>0$. The retailer's utility is a power function $U(x)=x^{k}$ for some $0<k<1$. The retailer is more risk averse when $k$ is smaller.

The following proposition gives the RE equilibrium order quantity and retail price for risk-averse newsvendor in the previous situation.

Proposition 4. Suppose that $F(x)$ is uniform distribution and $U(y)=y^{k}$. In the RE equilibrium, all consumers buy immediately, and the risk-averse retailer's price and quantity are

$$
\begin{gathered}
p_{\mathrm{ra}}=s+\frac{\sqrt{(c-s)^{2}+4 k(c-s)(v-s)}-(c-s)}{2 k}, \\
\mathrm{Q}_{\mathrm{ra}}=\frac{A\left(\sqrt{(c-s)^{2}+4 k(c-s)(v-s)}-(c-s)\right)}{\sqrt{(c-s)^{2}+4 k(c-s)(v-s)}+c-s} .
\end{gathered}
$$

Proof. The RE equilibrium condition (11) and $U(x)=x^{k}(0<$ $k<1$ ) reduce to

$$
\begin{aligned}
& \frac{d E[U(\pi(Q))]}{d Q} \\
& =-k(c-s) \int_{((c-s) /(p-s)) Q}^{Q}((p-s) x-(c-s) Q)^{k-1} f(x) d x \\
& \quad+k(p-c) \int_{Q}^{+\infty}((p-c) Q)^{k-1} f(x) d x .
\end{aligned}
$$

Notice that the distribution of stochastic demand $\xi$ is uniform on $[0, A]$. Consider that $f(x)=1 / A$, and so

$$
\begin{aligned}
& \frac{d E[U(\pi(Q))]}{d Q} \\
& =-k(c-s) \int_{((c-s) /(p-s)) Q}^{Q} \frac{((p-s) x-(c-s) Q)^{k-1}}{A} d x \\
& \quad+k(p-c) \int_{Q}^{A} \frac{((p-c) Q)^{k-1}}{A} d x .
\end{aligned}
$$

According to $d E[U(\pi(Q))] / d Q=0$, we have

$$
Q=\frac{A k(p-s)}{k(p-s)+(c-s)} .
$$

From the RE equilibrium condition (10), we know that

$$
p=v-(v-s) F(Q) \text {. }
$$

So,

$$
(p-v)(k(p-s)+c-s)^{2}+k^{2}(p-s)^{2}(v-s)=0 .
$$

Let $p-v=p-s-(v-s)$. The previous equation becomes equivalently as

$$
k(p-s)+(p-s)(c-s)-(v-s)(c-s)=0 .
$$

Solving the previous equation yields the desired results. 
The impact of unit ordering cost and customer valuation on the rational equilibrium price and order quantity for risk-averse newsvendor in the case where demand follows the uniform distribution and utility is power function are summarized in the following proposition.

Proposition 5. Suppose that $F(x)$ is uniform distribution and $U(y)=y^{k}$. In RE equilibrium for risk-averse newsvendor, (i) both the retail price $p_{\mathrm{ra}}$ and the ordering quantity $Q_{\mathrm{ra}}$ are increasing in customer valuation.

(ii) The price $p_{\mathrm{ra}}$ in RE equilibrium for risk-averse newsvendor is increasing in ordering cost, while the ordering quantity $Q_{\mathrm{ra}}$ is decreasing in ordering cost.

Proof. From Proposition 4 and

$$
\begin{gathered}
p_{\mathrm{ra}}=s+\frac{2(v-s)}{\sqrt{1+4 k((v-s) /(c-s))}+1}, \\
Q_{\mathrm{ra}}=A\left(1-\frac{2}{\sqrt{1+4 k((v-s) /(c-s))}+1}\right),
\end{gathered}
$$

the desired results are straight.

This result is similar to the risk-neutral case.

The following proposition compares the RE equilibrium order quantity and price for risk-averse newsvendor with the optimal ordering quantity and retail price for riskaverse newsvendor with myopic customers in the case where demand follows the uniform distribution and utility is power function.

Proposition 6. (i) The price $p_{\mathrm{ra}}$ in RE equilibrium is higher than $c$ and lower than $v$.

(ii) The ordering quantity $Q_{\mathrm{ra}}$ in $R E$ equilibrium is lower than a risk-averse newsvendor model with myopic customers.

Proof. From the RE equilibrium condition (10), we know that $p_{\text {ra }}<v$. The equation (16) can be reduced to

$$
\frac{p_{\mathrm{ra}}-s}{c-s}=\frac{\sqrt{1+4 k((v-s) /(c-s))}-1}{2 k} .
$$

To obtain the relationship between $p_{\text {ra }}$ and $c$, we define a function

$$
l(x)=\frac{\sqrt{1+4 x((v-s) /(c-s))}-1}{2 x} .
$$

The derivative of $l(x)$ is

$$
l^{\prime}(x)=\frac{-1-2 x((v-s) /(c-s))}{2 x^{2} \sqrt{1+4 k((v-s) /(c-s))}}<0 .
$$

Hence,

$$
\begin{aligned}
l(x) & <l(0) \\
& =\lim _{k \rightarrow 0^{+}} \frac{\sqrt{1+4 x((v-s) /(c-s))}-1}{2 x}=\frac{v-s}{c-s}>1
\end{aligned}
$$

for $x \in(0,1)$. Therefore $p_{\text {ra }}>c$.
From the proof of Proposition 3, we know that the optimal ordering quantity in the risk-averse newsvendor model with myopic customers is

$$
Q_{0}=\frac{A k(v-s)}{k(v-s)+(c-s)}=A\left(1-\frac{1}{k((v-s) /(c-s))+1}\right) .
$$

To obtain the relationship between $Q_{\mathrm{ra}}$ and $Q_{0}$, we define a function

$$
g(x)=\frac{\sqrt{1+4 x((v-s) /(c-s))}+1}{x((v-s) /(c-s))+1} .
$$

Then we have

$$
\begin{aligned}
& g^{\prime}(x) \\
& =\left(\frac{v-s}{c-s}\right)\left(1-2\left(\frac{v-s}{c-s}\right) x\right. \\
& \left.\quad-\sqrt{1+4 x\left(\frac{v-s}{c-s}\right)}\right) \\
& \quad \times\left(\left(x\left(\frac{v-s}{c-s}\right)+1\right)^{2} \sqrt{1+4 x\left(\frac{v-s}{c-s}\right)}\right)^{-1} \\
& <0 .
\end{aligned}
$$

Hence, $g(x)<g(0)=2$ for $x \in(0,1)$.

Notice that $Q_{\mathrm{ra}}=A(1-(2 / \sqrt{1+4 k((v-s) /(c-s))}+1))$. Therefore, $Q_{\mathrm{ra}}<Q_{0}$.

The previous proposition suggests that the impact of strategic customers on risk-averse newsvendor equilibrium decisions is the same as in the risk-neutral newsvendor. In term of price, strategic consumer behavior forces the risk-averse newsvendor to price below $v$ in order to induce the strategic consumers to purchase the product in the regular sale period. Next, in term of quantity, the equilibrium stocking quantity $Q_{\mathrm{ra}}$ for the risk-averse newsvendor is also lower than in the standard risk-averse newsvendor model for the purpose of increasing customers' willingness to pay.

The following proposition characterizes the impact of the level of risk aversion on the RE equilibrium price and order quantity for risk-averse newsvendor.

From (7), we know that the RE equilibrium order quantity for the risk-neutral retailer is

$$
Q_{\mathrm{rn}}=A\left(1-\sqrt{\frac{c-s}{v-s}}\right) .
$$

Proposition 7. (i) The RE equilibrium price $p_{\mathrm{ra}}$ is increasing in the degree of risk aversion.

(ii) For fixed $s, v$, and $c$, there exists a threshold $k_{0}=1-$ $\sqrt{(c-s) /(v-s)}$ such that the RE equilibrium price $p_{\text {ra }}$ is not greater than $p_{\text {rn }}$ for $k \geq k_{0}$.

(iii) The $R E$ equilibrium ordering quantity $Q_{\mathrm{ra}}$ is decreasing in the degree of risk aversion.

(iv) For fixed $s, v$, and $c$, there exists a threshold $k_{1}=k_{0}$ such that the RE equilibrium price $Q_{\mathrm{ra}}$ is not smaller than $Q_{\mathrm{rn}}$ for $k \geq k_{1}$. 
Proof. The derivative of $p_{\text {ra }}$ with respect to $k$ can be written as

$$
\begin{aligned}
\frac{d p_{\mathrm{ra}}}{d k}= & \frac{c-s}{2 k^{2}}-\frac{(c-s)^{2}+2 k(c-s)(v-s)}{2 k^{2} \sqrt{(c-s)^{2}+4 k(c-s)(v-s)}} \\
= & \frac{(c-s) \sqrt{(c-s)^{2}+4 k(c-s)(v-s)}}{2 k^{2} \sqrt{(c-s)^{2}+4 k(c-s)(v-s)}} \\
& -\frac{(c-s)^{2}+2 k(c-s)(v-s)}{2 k^{2} \sqrt{(c-s)^{2}+4 k(c-s)(v-s)}} \\
< & \frac{(c-s)^{2}+2 k(c-s)(v-s)}{2 k^{2} \sqrt{(c-s)^{2}+4 k(c-s)(v-s)}} \\
& -\frac{(c-s)^{2}+2 k(c-s)(v-s)}{2 k^{2} \sqrt{(c-s)^{2}+4 k(c-s)(v-s)}}=0 .
\end{aligned}
$$

Therefore, $p_{\text {ra }}$ is decreasing in $k$.

Note that

$$
\begin{aligned}
& \lim _{k \rightarrow 0^{+}} p_{\mathrm{ra}} \\
& \quad=\lim _{k \rightarrow 0^{+}} \frac{2(c-s)(v-s)}{\sqrt{(c-s)^{2}+4 k(c-s)(v-s)}+c-s}+s=v, \\
& \lim _{k \rightarrow 1^{-}} p_{\mathrm{ra}} \\
& \quad=s+\frac{2 \sqrt{(c-s)(v-s)}}{\quad} \\
& \quad s+\frac{\sqrt{(c-s)^{2}+4(c-s)(v-s)}-(c-s)}{\sqrt{((c-s) /(v-s))+4}+\sqrt{(c-s) /(v-s)}} \\
& <s+\sqrt{(c-s)(v-s)}=p_{\mathrm{rn}},
\end{aligned}
$$

we know that there exists $k_{0}$ such that the RE equilibrium price $p_{\text {ra }}$ is not greater than $p_{\text {rn }}$ for $k \geq k_{0}$ and not smaller than $p_{\text {rn }}$ for $k \leq k_{0}$. Solving the equation $p_{\text {ra }}=p_{\text {rn }}$ yields the $k_{0}$. function

To obtain the relationship between $Q_{\mathrm{ra}}$ and $k$, we define a

$$
h(k)=\sqrt{(c-s)^{2}+4 k(c-s)(v-s)} .
$$

Taking derivative of $Q_{\mathrm{ra}}$ with $k$ leads to

$$
\frac{d Q_{\mathrm{ra}}}{d k}=\frac{2 A h^{\prime}(k)(c-s)}{(h(k)+c-s)^{2}} .
$$

Since

$$
h^{\prime}(k)=\frac{2(c-s)(v-s)}{h(k)},
$$

we have

$$
\frac{d Q_{\mathrm{ra}}}{d k}>0
$$

Hence, $Q_{\mathrm{ra}}$ is increasing in $k$. Moreover, since $\lim _{k \rightarrow 0^{+}} Q_{\mathrm{ra}}=$ 0 and

$$
\begin{aligned}
\lim _{k \rightarrow 1^{-}} Q_{\mathrm{ra}} & =\frac{A(\sqrt{1+4((v-s) /(c-s))}-1)}{\sqrt{1+4((v-s) /(c-s))}+1} \\
& =A\left(1-\frac{2}{\sqrt{1+4((v-s) /(c-s))}+1}\right) \\
& >A\left(1-\sqrt{\frac{c-s}{v-s}}\right)=Q_{\mathrm{rn}},
\end{aligned}
$$

there exists $k_{1}$ such that the RE equilibrium ordering quantity $Q_{\mathrm{ra}}$ is not smaller than $Q_{\mathrm{rn}}$ for $k \geq k_{1}$ and not greater than $Q_{\mathrm{rn}}$ for $k \leq k_{1}$. Solving the equation $Q_{\mathrm{ra}}=Q_{\mathrm{rn}}$ yields the $k_{1}=k_{0}$.

Eeckhoudt et al. [20] investigated the classic newsvendor model with increasing, concave, and thrice differentiable utility functions and showed that the optimal ordering quantity in their environment is smaller than the risk-neutral optimal ordering quantity and decreases in risk-aversion level. Keren and Pliskin [21] derived the first order conditions for optimality for the problem of a risk-averse expected-utility maximizer newsvendor. They solved a special case where the utility function is any increasing differentiable function, and the random demand is uniformly distributed by this condition. They also claimed that a risk-averse newsvendor with a uniformly more concave utility function sets his order quantity to a lower value than a less risk-averse newsvendor, so a risk-averse newsvendor with a concave utility function sets order quantity less than a newsvendor who is risk neutral. From Proposition 7, we find that this may not be true when the strategic consumer behavior is incorporated into the classic newsvendor model. The RE equilibrium order quantity for some risk-averse newsvendor with the uniform distribution demand and power utility will order more than the risk-neutral newsvendor. In addition, together with the results in Proposition 6 we know that the optimal ordering quantity for some risk-averse newsvendor facing myopic consumers is higher than in risk-neutral retailer.

In Agrawal and Seshadri [22] it is assumed that the customers are myopic and if the realized demand is greater than the ordered quantity, the retailer can make emergency orders at a higher price $(>c)$ to meet the extra demand. And if the realized demand is less than the order quantity, the leftover inventory can be salvaged at a value that is not more than the cost. So the risk is mainly stemmed from overstock and some emergency purchase cost occurs for larger demand. Agrawal and Seshadri [22] showed that for the multiplicative model, the optimal price for a risk-averse retailer is not lower than that for a risk-neutral retailer and the optimal order quantity for a risk-averse retailer is smaller than that for a risk-neutral retailer. For the additive demand model, Agrawal and Seshadri [22] claimed that the optimal price is lower 
when the retailer is more risk averse, and the impact of risk aversion on the optimal order quantity is unclear. In our model, the equilibrium retail price is larger when the retailer is more risk averse, and the equilibrium order quantity is smaller when the retailer is more risk averse when he or she faces strategic consumers. The RE equilibrium retail price for some risk-averse newsvendors is lower than for the riskneutral newsvendors.

The impacts of salvage value on the RE equilibrium price and order quantity for risk-averse newsvendor in the case where demand follows the uniform distribution and utility is power function are summarized in the following proposition.

Proposition 8. (i) The $R E$ equilibrium retail price $p_{\mathrm{ra}}$ is decreasing in salvage price when $v \geq(4 k+2) c$, and there is a threshold $s_{0}$ such that $p_{\mathrm{ra}}$ is decreasing in $s$ for $s_{0}<s<c$ and is increasing in $s$ for $0<s \leq s_{0}$ when $v<(4 k+2) c$.

(ii) The RE equilibrium ordering quantity $Q_{r a}$ is increasing in salvage value.

Proof. The first and second derivatives of $p_{\text {ra }}$ with respect to $s$ are, respectively,

$$
\begin{aligned}
\frac{d p_{\mathrm{ra}}}{d s}= & 1+\frac{1}{2 k}-\frac{(2 k+1)(c-s)+2 k(v-s)}{2 k \sqrt{(c-s)^{2}+4 k(c-s)(v-s)}}, \\
\frac{d^{2} p_{\mathrm{ra}}}{d s^{2}}= & \frac{4 k+1}{2 k \sqrt{(c-s)^{2}+4 k(c-s)(v-s)}} \\
& -\frac{[(2 k+1)(c-s)+2 k(v-s)]^{2}}{2 k\left[(c-s)^{2}+4 k(c-s)(v-s)\right]^{3 / 2}} \\
= & -\frac{4 k^{2}(v-c)^{2}}{2 k\left[(c-s)^{2}+4 k(c-s)(v-s)\right]^{3 / 2}}<0 .
\end{aligned}
$$

Hence, $p_{\text {ra }}$ is concave in $s$. Notice that

$$
\begin{aligned}
\lim _{s \rightarrow c^{-}} \frac{d p_{\mathrm{ra}}}{d s}= & +\frac{1}{2 k} \\
& \quad-\lim _{s \rightarrow c^{-}} \frac{(2 k+1)(c-s)+2 k(v-s)}{2 k \sqrt{(c-s)^{2}+4 k(c-s)(v-s)}}=-\infty \\
\lim _{s \rightarrow 0^{+}} \frac{d p_{\mathrm{ra}}}{d s} & \\
= & 1+\frac{1}{2 k}-\lim _{s \rightarrow 0^{+}} \frac{(2 k+1)(c-s)+2 k(v-s)}{2 k \sqrt{(c-s)^{2}+4 k(c-s)(v-s)}} \\
= & 1+\frac{1}{2 k}-\frac{(2 k+1) c+2 k v}{2 k \sqrt{c^{2}+4 k c v}} \\
= & 2 k\left((4 k+2) c v-v^{2}\right) \\
& \times\left(\sqrt{c^{2}+4 k c v}\right. \\
& \left.\quad \times\left((2 k+1) \sqrt{c^{2}+4 k c v}+((2 k+1) c+2 k v)\right)\right)^{-1} .
\end{aligned}
$$

Therefore $\left(d p_{\mathrm{ra}} / d s\right)<0$ for $v \geq(4 k+2) c$, and $p_{\text {ra }}$ is decreasing in $s$ for any $s \in(0, c) . \lim _{s \rightarrow 0^{+}}\left(d p_{\mathrm{ra}} / d s\right)>0$ for $v<(4 k+2) c$. Note that $p_{\text {ra }}$ is concave in $s$. We know that there exists a point $s_{0}$ in $(0, c)$ such that $\left(d p_{\mathrm{ra}} / d s\right)<0$ for $s \in\left(s_{0}, c\right)$ and $\left(d p_{\mathrm{ra}} / d s\right)>0$ for $s \in\left(0, s_{0}\right)$. It is easy to see that $p_{\mathrm{ra}}$ is decreasing in $s \in\left(s_{0}, c\right)$ and $p_{\mathrm{ra}}$ is increasing in $s \in\left(0, s_{0}\right)$.

To obtain the relationship between $Q_{\mathrm{ra}}$ and $s$, we define

$$
g(s)=\sqrt{(c-s)^{2}+4 k(c-s)(v-s)} .
$$

Then we have

$$
g^{\prime}(s)=-\frac{(2 k+1)(c-s)+2 k(v-s)}{g(s)} .
$$

Notice that

$$
\frac{d Q_{\mathrm{ra}}}{d s}=\frac{2 A\left(g(s)+g^{\prime}(s)(c-s)\right)}{(g(s)+c-s)^{2}} .
$$

We have

$$
\begin{aligned}
& \frac{d Q_{\mathrm{ra}}}{d s} \\
& =\frac{2 A\left(g^{2}(s)-(2 k+1)(c-s)^{2}-2 k(v-s)(c-s)\right)}{g(s)(g(s)+c-s)^{2}} \\
& =\frac{4 k A\left((c-s)(v-s)-(c-s)^{2}\right)}{g(s)(g(s)+c-s)^{2}}>0 .
\end{aligned}
$$

So, $Q_{\mathrm{ra}}$ is increasing in $s$ on $(0, c)$.

Proposition 8 characterizes the impacts of salvage value on equilibrium price and quantity. Chen et al. [26] used conditional value at risk as a risk-averse measure to investigate the combined pricing and ordering problem for newsvendor facing myopic customers. They showed that for the multiplicative demand, the optimal price for a risk-averse retailer is strictly increasing in $s$ under some mild conditions. For the additive demand, they claimed that the optimal price is strictly increasing in $s$ without any condition. On the other hand, Proposition 2 presents that the RE equilibrium price for risk-neutral newsvendor is strictly increasing in $s$. Contrary to the previous results, our findings show that risk-averse newsvendor is not always setting higher RE equilibrium retail price for larger salvage price. The relationship between them is dependent on other system parameters such as product cost, customer valuation, and risk-averse degree. Specifically, RE equilibrium price $p_{\text {ra }}$ is decreasing in salvage price when the product cost $c$ is sufficiently low or when the customer valuation $v$ is sufficiently high. Otherwise, there exists a threshold for $s$. The RE equilibrium retail price is decreasing in salvage price when the salvage price is higher than the threshold and is increasing in salvage price otherwise. That is, to say that the RE equilibrium retail price for the risk-averse newsvendor in our model is increasing in salvage price only for the situation in which the product cost is sufficiently high, customer valuation is sufficiently low relatively to product 


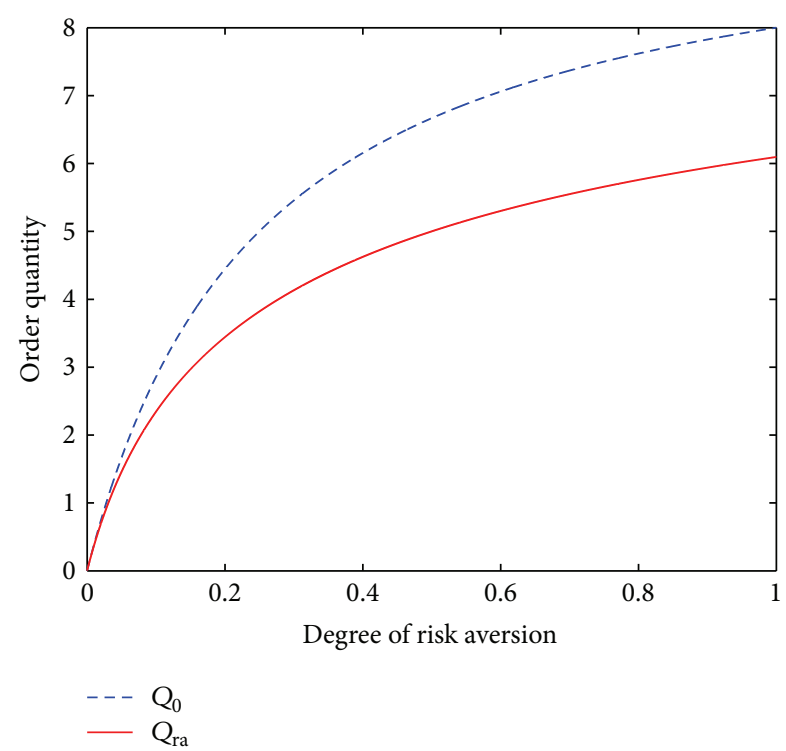

FIgURE 1: The effect of risk-averse level on $Q_{0}$ and $Q_{\mathrm{ra}}$.

cost, and salvage price is low. In addition, there exists a threshold for risk-averse level $k$ for reasonable fixed $v$ and $c$. That is, the RE equilibrium retail price is decreasing in salvage price for more risk-averse retailer, and the relation between the RE equilibrium sale price and salvage price for a less riskaverse retailer depends on the threshold for $s$.

\section{Numerical Examples}

In this section, we present some numerical examples to illustrate how the RE equilibrium price and quantity are affected by the degree of risk-aversion and salvage price.

Firstly, we analyze the impact of risk-averse level on $\mathrm{RE}$ equilibrium quantity and price. Suppose that random demand $\xi$ is uniform distribution on $[0,10], v=10, c=4$, and $s=2$. Then $Q_{\mathrm{rn}}=5$ and $p_{\mathrm{rn}}=6$. According to (17), (20), and (32), we know that

$$
\begin{gathered}
p_{\mathrm{ra}}=2+\frac{\sqrt{1+16 k}-1}{k}, \\
Q_{\mathrm{ra}}=\frac{5(\sqrt{1+16 k}-1)^{2}}{8 k}, \\
Q_{0}=\frac{40 k}{4 k+1} .
\end{gathered}
$$

From Figures 1 and 2, we find that $Q_{0}>Q_{\text {ra }}$ and $p_{\text {ra }}<v$ for $k \in(0,1)$ so as to induce the customers to purchase the product by lowering the sale price and generating scarcity and competition among them through restricting the availability of the product and maintaining an image of exclusivity. In addition, $Q_{0}$ and $Q_{\mathrm{ra}}$ are increasing in $k$, and $p_{\mathrm{ra}}$ is decreasing in $k$.

Solving $p_{\mathrm{ra}}=p_{\mathrm{rn}}, Q_{\mathrm{ra}}=Q_{\mathrm{rn}}$, and $Q_{0}=Q_{\mathrm{rn}}$, we get $k_{0}=0.5, k_{1}=0.5$, and $k_{2}=0.25$. So $p_{\text {ra }}$ is lower

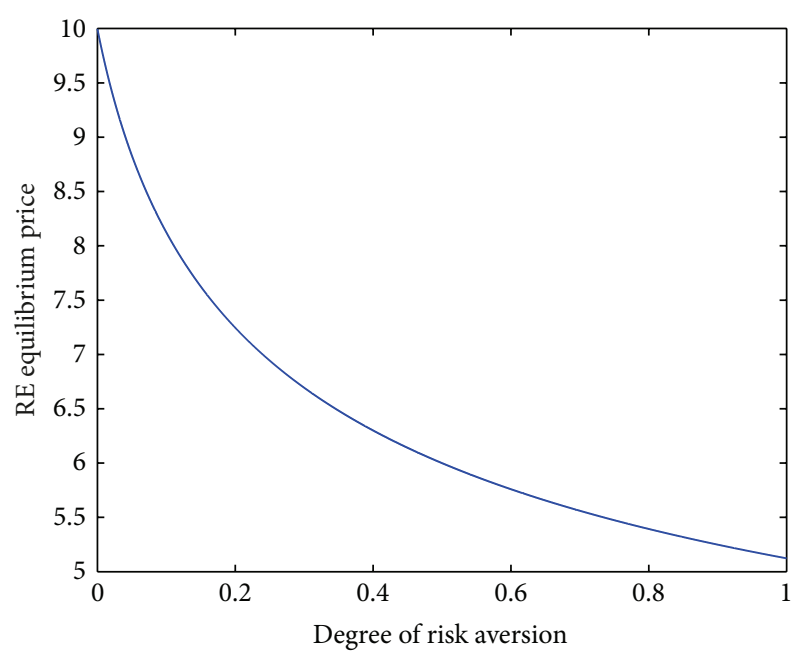

Figure 2: The effect of risk-averse level on $p_{\text {ra }}$.

than $p_{\mathrm{rn}}$ for $k \in(0.5,1)$, and $Q_{\mathrm{ra}}$ is higher than $Q_{\mathrm{rn}}$ for $k \in(0.5,1)$. Furthermore, $Q_{\mathrm{ra}}$ is higher than $Q_{\mathrm{rn}}$ for $k \in$ $(0.25,1)$. These results are contrary to usual results for riskaverse newsvendor relative to risk-neutral retailer when he faces myopic newsvendor.

In what follows, we investigate the influence of salvage price on the RE equilibrium price and quantity with the same parameters as mentioned previously. According to (16) and (17), we know that

$$
\begin{gathered}
p_{\mathrm{ra}}=s+\frac{\sqrt{(4-s)^{2}+4 k(4-s)(10-s)}-(4-s)}{2 k}, \\
Q_{\mathrm{ra}}=\frac{10\left(\sqrt{(4-s)^{2}+4 k(4-s)(10-s)}-(4-s)\right)}{\sqrt{(4-s)^{2}+4 k(4-s)(10-s)}+4-s} .
\end{gathered}
$$

Solving the equation $v=(4 k+2) c$, we get $k^{*}=0.125$. Let $k=0.1, k=0.05$, and $k=0.025$ in Figure 3; we find that the $\mathrm{RE}$ equilibrium price is decreasing in salvage price. Let $k=0.2, k=0.6$, and $k=0.8$ in Figure 4; we find that the RE equilibrium price is firstly increasing in salvage price and then decreasing. In Figure 5, we observe that the RE equilibrium quantity is decreasing in salvage price.

In addition, we notice that $s_{0}$ is increasing in $k$ from Figure 4 . Letting $\left(d p_{\mathrm{ra}} / d s\right)=0$ where $k>k^{*}$, we can obtain the following equation:

$$
1+\frac{1}{2 k}-\frac{(2 k+1)\left(4-s_{0}\right)+2 k\left(10-s_{0}\right)}{2 k \sqrt{\left(4-s_{0}\right)^{2}+4 k\left(4-s_{0}\right)\left(10-s_{0}\right)}}=0 .
$$

Its solution is $s_{0}=4-6 /(4 k+1)$. So, the changes of $s_{0}$ with $k$ is consistent with our observation. That is to say that the range 


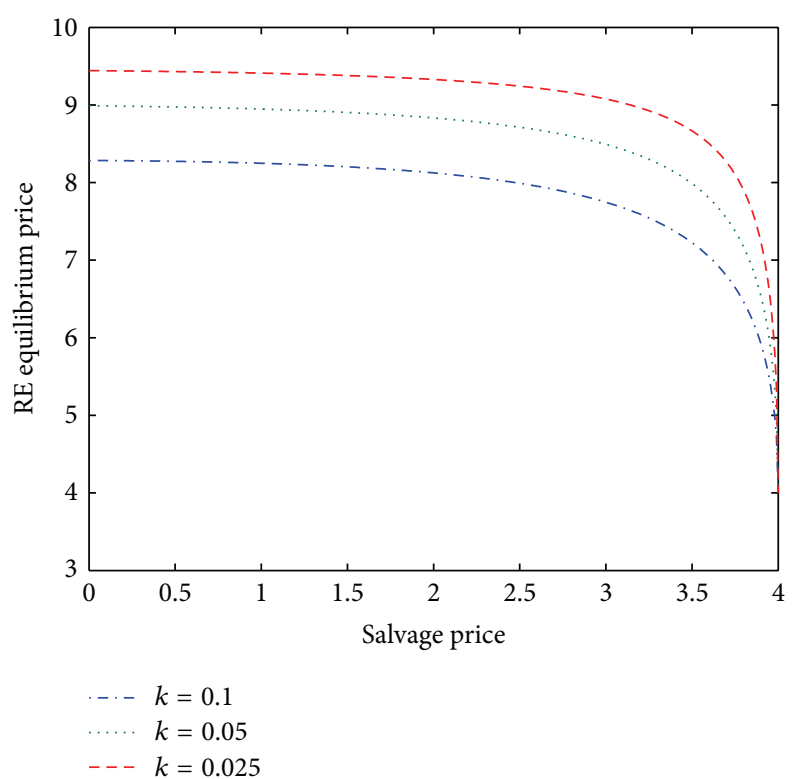

FIGURE 3: The effect of salvage price on $p_{\text {ra }}$ when $k \leq k^{*}$.

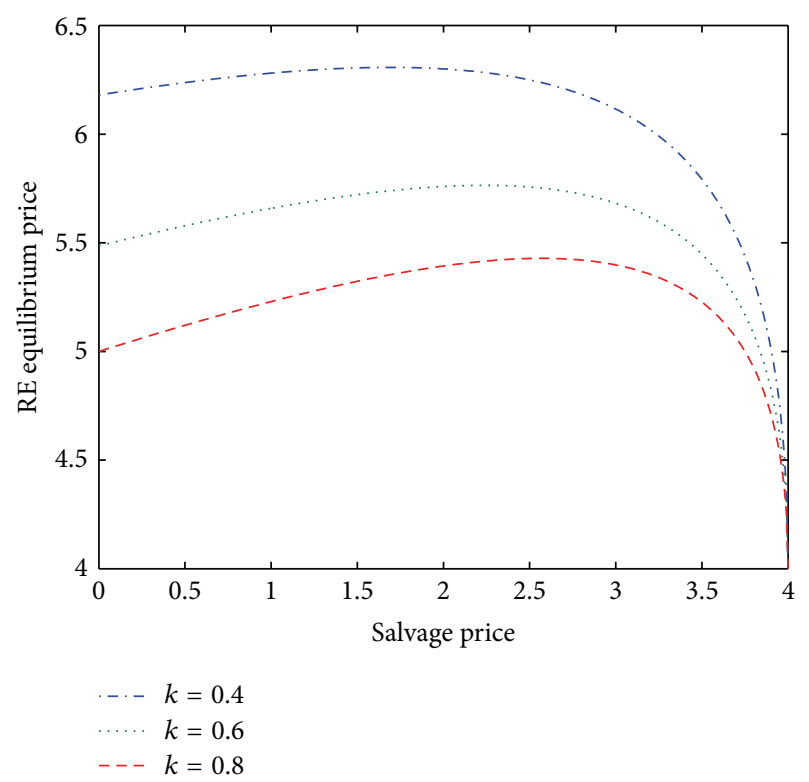

FIGURE 4: The effect of salvage price on $p_{\mathrm{ra}}$ when $k>k^{*}$.

is more narrow for more risk-averse retailer in which the RE equilibrium price is increasing in salvage price.

\section{Conclusions}

This paper investigates the RE equilibrium decisions for the risk-averse newsvendor facing strategic consumers. One of our basic premises is that the newsvendor is risk averse another is that consumers look ahead and plan purchases with future opportunities in mind. To derive structural results and generate managerial insights into the equilibrium decisions of the risk-averse newsvendor problem with strategic

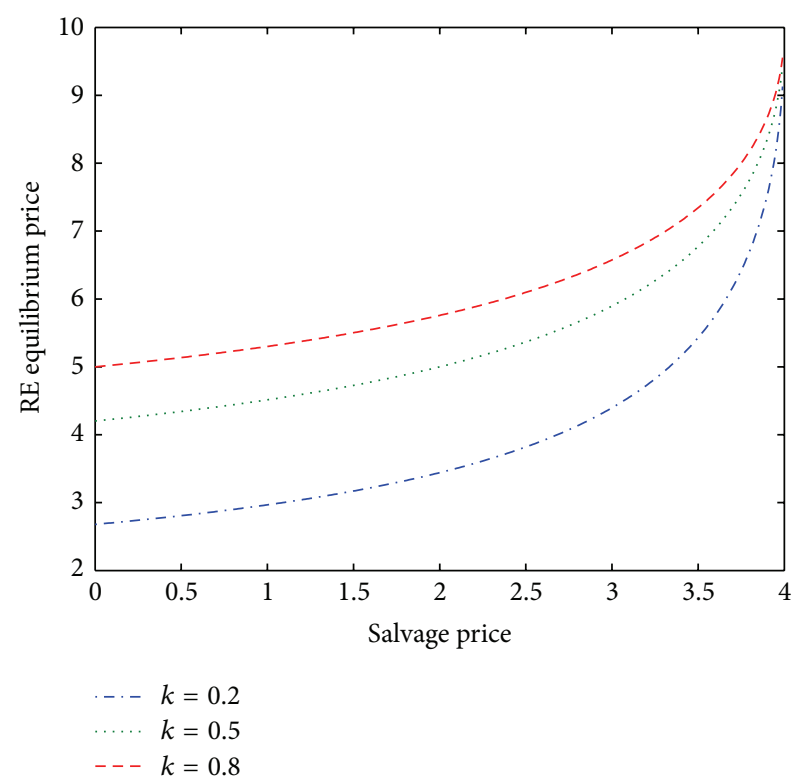

FIgURE 5: The effect of salvage price on $Q_{\mathrm{ra}}$.

consumers, we present specific results for the situation in which demand is a uniformly distributed and utility is a general power function. We obtain the analytical representations for the RE equilibrium price and quantity and perform the sensitivity analysis to investigate the impacts of ordering cost, salvage price, and degree of risk-aversion on the equilibrium. Our analysis complements the work in the literature and offers managerial insights to the practitioners or managers. We show that the optimal ordering quantity for some risk-averse newsvendor facing myopic consumers is higher than the RE equilibrium ordering quantity for a riskneutral retailer, and the $\mathrm{RE}$ equilibrium retail price for some risk-averse newsvendor is lower than the RE equilibrium price for risk-neutral retailer, and the stocking quantity in $\mathrm{RE}$ equilibrium for some risk-averse newsvendor is higher than the RE equilibrium price for risk-neutral retailer. We also find the conditions under which the sale price in RE equilibrium for risk-averse newsvendor is decreasing in salvage price.

The problem studied here can further be researched in several directions. First, it is meaningful to make clear of the value of price commitment and quantity commitment for risk-averse newsvendor facing strategic consumer and the impacts of contracts on decentralized supply chain with risk-averse newsvendor facing forward-looking customers. Second, it is important to investigate the combined effects of risk-averse level of consumer, consumer's forward-looking purchasing behavior, and degree of risk aversion for newsvendor. Finally, investigating the optimal decisions for riskaverse newsvendor facing strategic consumers in competitive setting would be a very interesting topic.

\section{Acknowledgment}

This work is partially supported by National Natural Science Foundation of China (no. 71271059). 


\section{References}

[1] M. E. Schweitzer and G. P. Cachon, "Decision bias in the newsvendor problem with a known demand distribution: experimental evidence," Management Science, vol. 46, no. 3, pp. 404-421, 2000.

[2] J. F. Muth, "Rational expectations and the theory of price movements," Econometrica, vol. 29, pp. 315-335, 1961.

[3] M. Khouja, "The single-period (news-vendor) problem: literature review and suggestions for future research," Omega, vol. 27, no. 5, pp. 537-553, 1999.

[4] N. C. Petruzzi and M. Dada, "Pricing and the newsvendor problem: a review with extensions," Operations Research, vol. 47, no. 2, pp. 183-194, 1999.

[5] L. Yao, Y. Chen, and H. Yan, "The newsvendor problem with pricing: extensions," International Journal of Management Science and Engineering Management, vol. 1, pp. 3-16, 2006.

[6] M. A. Lariviere and E. L. Porteus, "Selling to the newsvendor: an analysis of price-only contracts," Manufacturing and Service Operations Management, vol. 3, no. 4, pp. 293-305, 2001.

[7] Y. Gerchak and Y. Wang, "Periodic-review inventory models with inventory-level-dependent demand," Naval Research Logistics, vol. 41, no. 1, pp. 99-116, 1994.

[8] A. Balakrishnan, M. S. Pangburn, and E. Stavrulaki, “'Stack them high, let 'em fly': lot-sizing policies when inventories stimulate demand," Management Science, vol. 50, no. 5, pp. 630644, 2004.

[9] J. D. Dana Jr. and N. C. Petruzzi, "Note: the newsvendor model with endogenous demand," Management Science, vol. 47, no. 11, pp. 1488-1497, 2001.

[10] A. Balakrishnan, M. S. Pangburn, and E. Stavrulaki, "Integrating the promotional and service roles of retail inventories," Manufacturing and Service Operations Management, vol. 10, no. 2, pp. 218-235, 2008.

[11] S. Liu, K. C. So, and F. Zhang, "Effect of supply reliability in a retail setting with joint marketing and inventory decisions," Manufacturing and Service Operations Management, vol. 12, no. 1, pp. 19-32, 2010.

[12] T. A. Taylor, "Supply chain coordination under channel rebates with sales effort effects," Management Science, vol. 48, no. 8, pp. 992-1007, 2002.

[13] H. Krishnan, R. Kapuscinski, and D. A. Butz, "Coordinating contracts for decentralized supply chains with retailer promotional effort," Management Science, vol. 50, no. 1, pp. 48-63, 2004.

[14] Y. Gerchak and M. Parlar, "A Single period inventory problem with partially controllable demand," Computers and Operations Research, vol. 14, no. 1, pp. 1-9, 1987.

[15] M. Khouja and S. S. Robbins, "Linking advertising and quantity decisions in the single-period inventory model," International Journal of Production Economics, vol. 86, no. 2, pp. 93-105, 2003.

[16] S.-D. Wang and Y.-W. Zhou, "Supply chain coordination models for newsvendor-type products: considering advertising effect and two production modes," Computers and Industrial Engineering, vol. 59, pp. 220-231, 2011.

[17] S.-D. Wang, Y.-W. Zhou, and J.-P. Wang, "Supply chain coordination with two production modes and random demand depending on advertising expenditure and selling price," International Journal of Systems Science, vol. 41, no. 10, pp. 1257-1272, 2010.
[18] S.-D. Wang, Y.-W. Zhou, and J.-P. Wang, "Coordinating ordering, pricing and advertising policies for a supply chain with random demand and two production modes," International Journal of Production Economics, vol. 126, no. 2, pp. 168-180, 2010.

[19] H. S. Lau, "The newsboy problem under alternative optimization objectives," Operational Research Society Journal, vol. 31, no. 6, pp. 525-535, 1980.

[20] L. Eeckhoudt, C. Gollier, and H. Schlesinger, "The risk-averse (and prudent) newsboy," Management Science, vol. 41, pp. 786794, 1995.

[21] B. Keren and J. S. Pliskin, "A benchmark solution for the riskaverse newsvendor problem," European Journal of Operational Research, vol. 174, no. 3, pp. 1643-1650, 2006.

[22] V. Agrawal and S. Seshadri, "Impact of uncertainty and risk aversion on price and order quantity in the newsvendor problem," Manufacturing and Service Operations Management, vol. 2, no. 4, pp. 410-423, 2000.

[23] F. Chen and A. Federgruen, Mean-Variance Analysis of Basic Inventory Models. Working Paper, Columbia University, New York, NY, USA, 2000.

[24] T. Choi, D. Li, and H. Yan, "Mean-variance analysis for the newsvendot problem," IEEE Transactions on Systems, Man, and Cybernetics A, vol. 38, pp. 80-96, 2008.

[25] J.-Y. Gotoh and Y. Takano, "Newsvendor solutions via conditional value-at-risk minimization," European Journal of Operational Research, vol. 179, no. 1, pp. 80-96, 2007.

[26] Y. Chen, M. Xu, and Z. G. Zhang, "A risk-averse newsvendor model under the CVaR criterion," Operations Research, vol. 57, no. 4, pp. 1040-1044, 2009.

[27] S. Ahmed, U. Çakmak, and A. Shapiro, "Coherent risk measures in inventory problems," European Journal of Operational Research, vol. 182, no. 1, pp. 226-238, 2007.

[28] F. Gino and G. Pisano, "Toward a theory of behavioral operations," Manufacturing and Service Operations Management, vol. 10, no. 4, pp. 676-691, 2008.

[29] E. Bendoly, R. Croson, P. Goncalves, and K. Schultz, "Bodies of knowledge for research in behavioral operations," Production and Operations Management, vol. 19, no. 4, pp. 434-452, 2010.

[30] Z.-J. M. Shen and X. Su, "Customer behavior modeling in revenue management and auctions: a review and New Research Opportunities," Production and Operations Management, vol. 16, no. 6, pp. 713-728, 2007.

[31] X. Su, "Bounded rationality in newsvendor models," Manufacturing and Service Operations Management, vol. 10, no. 4, pp. 566-589, 2008.

[32] X. Su, "Intertemporal pricing with strategic customer behavior," Management Science, vol. 53, no. 5, pp. 726-741, 2007.

[33] X. Su and F. Zhang, "Strategic customer behavior, commitment, and supply chain performance," Management Science, vol. 54, no. 10, pp. 1759-1773, 2008.

[34] X. Su and F. Zhang, "On the value of commitment and availability guarantees when selling to strategic consumers," Management Science, vol. 55, no. 5, pp. 713-726, 2009.

[35] G. Lai, L. G. Debo, and K. Sycara, "Buy now and match later: impact of posterior price matching on profit with strategic consumers," Manufacturing and Service Operations Management, vol. 12 , no. 1, pp. 33-55, 2010. 


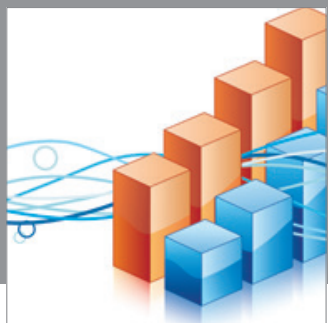

Advances in

Operations Research

mansans

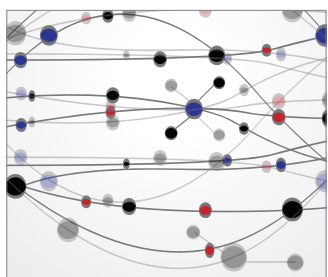

The Scientific World Journal
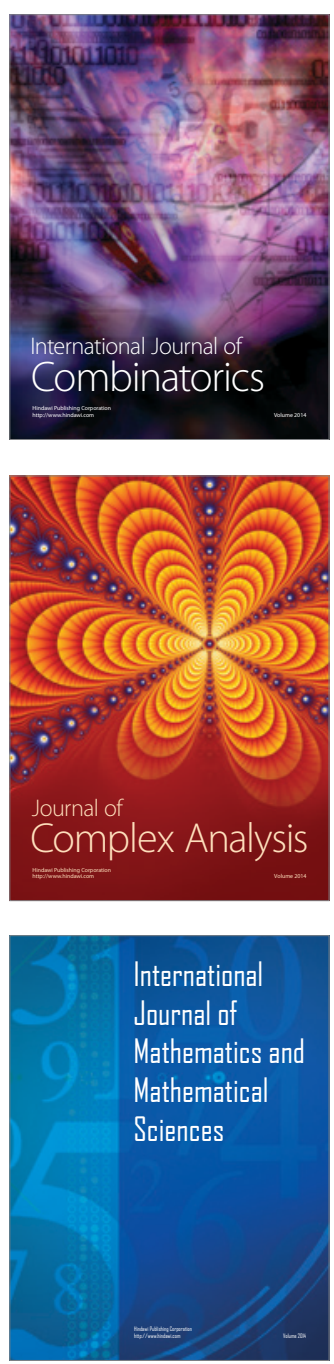
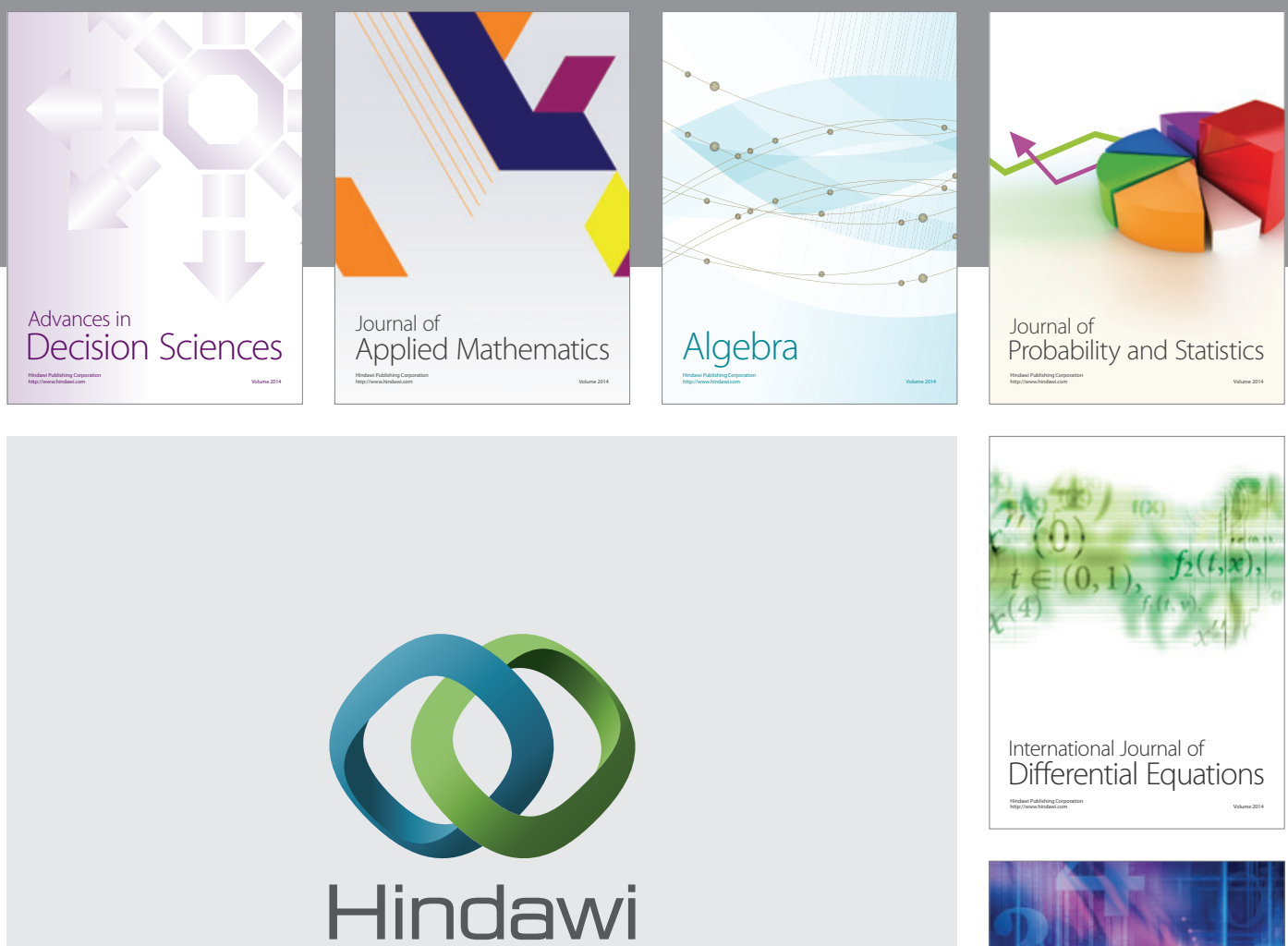

Submit your manuscripts at http://www.hindawi.com
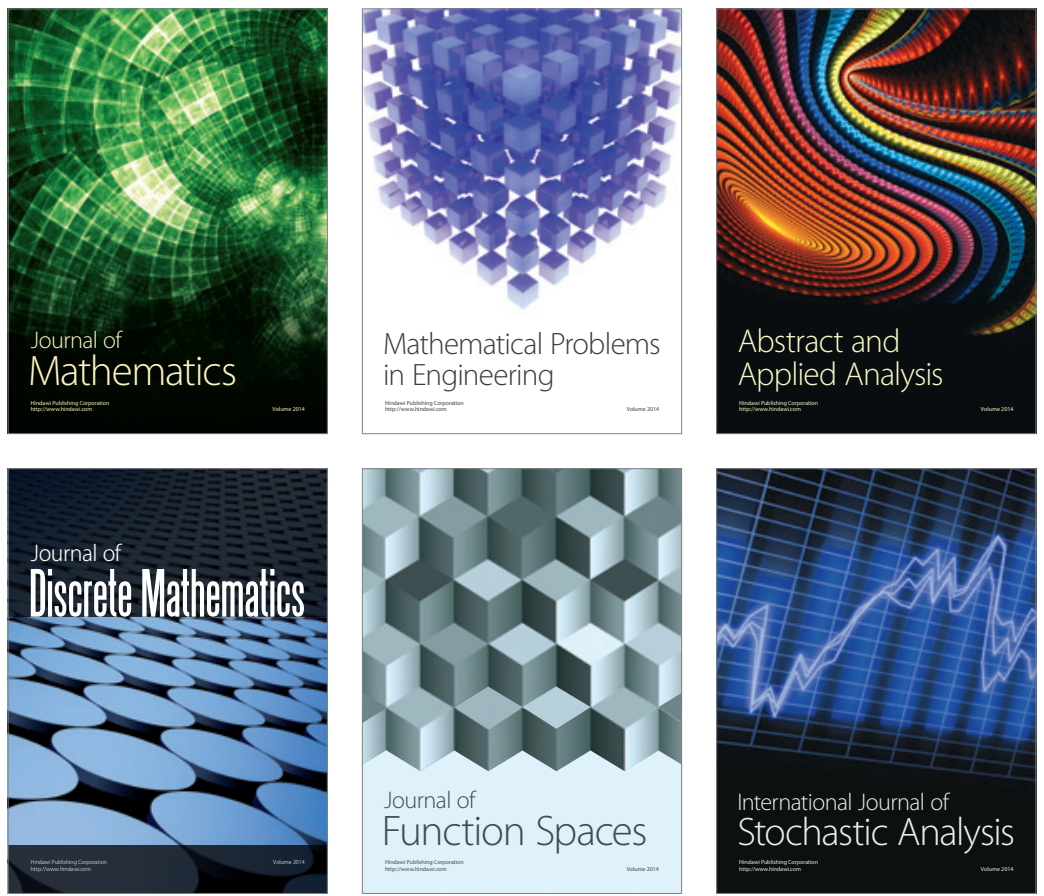

Journal of

Function Spaces

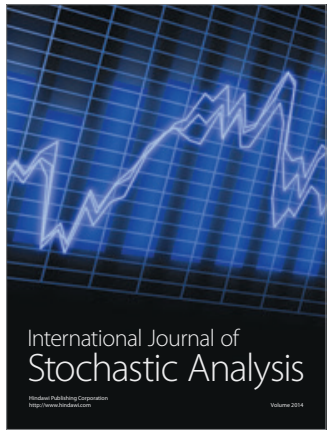

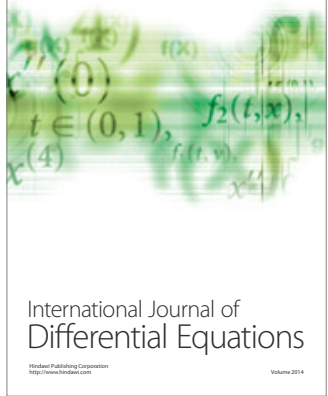
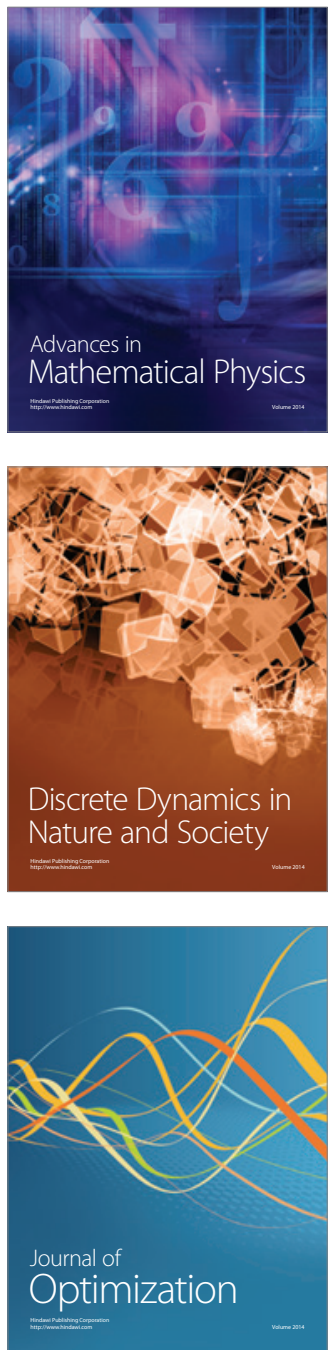